\title{
ОТОЖДЕСТВЛЕНИЕ-РАЗОТОЖДЕСТВЛЕНИЕ С СОБОЙ ПОСРЕДСТВОМ ДРУГОГО: ПАРАДОКС САМОТОЖДЕСТВА Я
}

\author{
Е.Б. СТАРОВОЙТЕНКО \\ ${ }^{a}$ Национальньй исследовательский университет «Высшая школа экономики», 101000, Россия, \\ Москва, ул. Мясницкая, д. 20
}

\section{Identification and De-Identification with I Through Other: Paradox of Self-Identity}

\author{
E.B. Starovoytenko \\ ${ }^{a}$ HSE University, 20 Myasnitskaya Str., Moscow, 101000, Russian Federation
}

\begin{abstract}
Резюме
Проблемой данного исследования является обоснование достижения личностью самотождества Я на основе процессов отождествления и разотождествления с собой посредством значимого Другого, в рефлексивном диалоге с ним. При решении проблемы был применен персонологический подход, состоящий в последовательном построении и взаимном преломлении концептуальной, культурно-феноменологической и рефлексивно-диалогической моделей отождествления и разотождествления Я с собой в отношении к Другому. Исследование имеет междисциплинарный характер, основывается на отечественных и зарубежных источниках, релевантных изучению самотождества Я.
\end{abstract}

\begin{abstract}
The research is focused on the problem of personality reaching its self-identity through identification and de-identification with the Self through the significant Other during a reflexive dialog. Personological approach was used to solve this problem, based on consistent creation and mutual refraction of conceptual, cultural-phenomenological and reflexive-dialogical models of identification and deidentification of I with Self in relation to the Other. The research is interdisciplinary in nature, based on domestic and foreign sources relevant to the study of self-identity. The article presents the results of an empirical study conducted with the
\end{abstract}

Публикация подготовлена в ходе проведения исследования (проект № 20-01-010) в рамках Программы «Научный фонд Национального исследовательского университета "Высшая школа экономики” (НИУ ВШЭ)» в 2020-2021 гг. и в рамках государственной поддержки ведущих университетов Российской Федерации 5-100.

The article was prepared within the framework (project number 18-013-01108) of the Basic Research Program at HSE University and funded by the Russian Academic Excellence Project '5-100' (2020-2021). 
Представлены результаты эмпирического исследования, проведенного методом рефлексивного интервью, посвященное изучению внутреннего диалога Я - Другой, предметом которого выступило качество респондентов «открытость опыту». Новизна исследования состоит, во-первых, в постановке вопроса о «самотождестве Я» в условиях парадоксально неразрывного единства отождествления-разотождествления с собой как противоположных «актов Я». Во-вторых, психологически осмысливается значение Другого в опосредовании актов отождествления и разотождествления Я с собой в рефлексивном диалоге Я - Другой. В-третьих, в существующее понимание генеза «диалогического Я» привносится идея «структуры измерений» внутреннего диалога Я Другой, рассматриваемого как динамика отождествления-разотождествления Я с собой. В-четвертых, процессы отождествления и разотождествления с собой и достижение самотождества Я анализируются с точки зрения поиска и раскрытия Я-неизвестного. В-пятых, результатом проведенного эмпирического исследования является определение форм самотождества Я в аспекте качества «открытости опыту», зависящих от выраженности и динамики отождествления-разотождествления Я с собой посредством Другого. К этим формам относятся развивающееся, становящееся, противоречивое, ригидное и регрессирующее самотождество.

Ключевые слова: Я, самотождество Я, отождествление, разотождествление, Другой, диалог, открытость опыту, парадокс, рефлексия, модели, культура, герменевтика, персонология.

Старовойтенко Елена Борисовна - руководитель центра, Центр фундаментальной и консультативной персонологии, департамент психологии, факультет социальных наук, Национальный исследовательский университет «Высшая школа экономики», доктор психологических наук, профессор.

Сфера научных интересов: методология психологии, теоретическая психология личности, персонология, психология жизненных отношений личности, культурная психология личности, психология рефлексии.

Контакты: heletstaOS@yandex.ru method of reflexive interviews and devoted to the research on internal dialogue between the Self and the Other; the subject of the study was the respondents' quality of "openness to experience." The novelty of the study consists, firstly, in raising the issue of self-identity in terms of paradoxically inseparable unity of identification and de-identification with the Self as opposite to self-actions. Secondly, the research offers psychological consideration of the importance of the Other in mediating the acts of identification and de-identification of I with Self during a reflexive dialog between I and the Other. Thirdly, the existing understanding of the genesis of the dialogical Self is enriched by the idea of the structure of dimensions of the internal dialog I Other, considered as the dynamics of identification and de-identification of I with the Self. Fourthly, the processes of identification and de-identification with the Self and reaching self-identity are analyzed from the point of view of search and discovery of the unknown Self. Fifthly, empirical research resulted in defining of the forms of selfidentity in the aspect of openness to experience, which depend on the level and dynamics of identification and de-identification of I with the Self though the Other. There are developing, maturing, controversial, rigid and regressing self-identity among those forms.

Keywords: I, Self, self-identity, identification, de-identification, Other, dialogue, openness to experience, paradox, reflection, models, culture, hermeneutics, personology.

Elena B. Starovoytenko - Professor, Head of the Centre for Fundamental and Consulting Personology, School of Psychology, Faculty of Social Sciences, HSE University, DSc in Psychology.

Research Area: methodology of psychology, theoretical psychology of personality, personology, psychology of life relationships of personality, cultural personality psychology, psychology of reflection.

E-mail: helestaOS@yandex.ru 


\section{Введение}

Замысел данной работы составляет обоснование достижения личностью самотождества Я на основе процессов отождествления и разотождествления с собой посредством значимого Другого в рефлексивном диалоге с ним.

Мы придерживались персонологического формата исследования (Петровский, Старовойтенко, 2012; Старовойтенко, 2015), применяя методы герменевтики и теоретического моделирования, культурно-феноменологический метод и метод рефлексивного интервью. Источниками изучения самотождества Я и способов его достижения, поддержания, развития стали работы зарубежных и отечественных исследователей, посвященные проблемам Я, самоидентичности личности в соотношении с идентичностью, личностного построения Я-концепции, роли Другого в динамике обретения и утраты Я идентичности с собой, условиям становления диалогического Я.

Новизна исследования состоит в постановке вопроса о «самотождестве Я» и условиях его развития, что позволяет привлечь к психологическому изучению Я не только работы из данной области науки, касающиеся «самоидентичности», но и классические философские тексты, расширенно трактующие самотождество как чувство, осознание и рефлексию совпадения Я с самим собой, как относительную устойчивость свойств и качеств Я для себя, как относительное постоянство Я во времени, как единство, последовательность собственной внутренней истории, создаваемой Я, как усилия воссоздания и обретения целостности и уникальности Я для себя. Другим моментом новизны представляемого исследования является акцент на непрерывность смены отождествления и разотождествления Я с собой и парадоксально неразрывное единство этих противоположных «актов Я», придающих динамизм и стабильность Я в его целостном ощущении, образе, чувстве, концепции и рефлексивной картине (Старовойтенко, 2019, 2020; Starovoytenko, 2020). В новом аспекте осмысливается значение Другого с его опосредованием актов отождествления и разотождествления Я с собой в рефлексивном диалоге Я Другой. Кроме того, в существующее понимание диалогичности Я привносится идея «структуры измерений» внутреннего диалога Я с Другим и с собой, которая уточняет концепцию генеза «диалогического Я», рассматривая его как результат отождествления-разотождествления Я со значимым другим, «включенным в Я», и достижения Я того или иного уровня самотождества на основе диалога. Новым является введение понятия «Я-неизвестное» (Старовойтенко, Щебетенко, 2020) в контекст анализа отождествления и разотождествления Я с собой как процессов поиска и выявления скрытых аспектов Я.

Обращаясь к процессам и эффектам достижения самотождества Я, мы обобщили ряд тенденций в близких к нашему замыслу областях современных психологических исследований.

В области изучения Я человека различаются истинное Я как представления Я о себе «в глубине души», «правда Я о себе», актуальное Я как осознание Я своих текущих действий и психических состояний, желаемое Я как сознание Я своих возможностей в перспективе реализации целей, понимаемое $Я$, 
определяемое как понятие о Я вообще, влияющее на знание личности об истинном, актуальном и желаемом Я, проявляющихся прежде всего в отношении близких других (Bem, 1972; Johnson et al., 2004; Schlegel et al., 2009; Anthony, McCabe, 2015; Strohminger et al., 2017). Развиваются положения об изменчивости Я и о множестве его форм в противовес идее «пунктуального

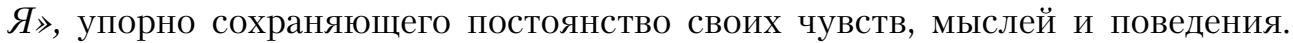
Изменчивое Я рассматривается как подвижный эффект возможностей, порожденных действиями в интерсубъективном и транссубъективном пространствах (Ginev, 2019).

В исследованиях самоидентичности подчеркивается ее становление путем идентификаций и самоинтерпретаций человека в отношениях с социумом, культурой, работой, телом, практиками, конкретными личностями, с собой; самоидентичность включается в число факторов, способствующих развитию этих отношений и уникальности человека (Tomassini, 2015). Изучаются единство и противоречия между самоидентичностью и социальными идентификациями личности (Андреева, 2009; Леонтьев, 2009; Белинская, 2018; Mallett, Wapshott, 2012; Iversen, 2019). Акцентируется взаимозависимость самоидентичности и построения Я-концепции (Breen et al., 2013). В частности, обнаруживается, что многомерность самоидентичности основана на расширении Яконцепции в отношениях с другими и на развитии у личности множества ее форм (Anthony, McCabe, 2015). Раскрывается роль значимого другого в обретении Я новой самоидентичности, в частности, при кардинальных изменениях социальной и профессиональной идентичностей человека (Emery et al., 2015; Grimell, 2018). Выделяется феномен «скучающего Я» как результат нереализации собственных стремлений личности, отсутствия у нее чувства самоизменений и переживания застоя идентичностей (Costas, Kдrreman, 2016). При изучении конфликтов идентичности и риска утраты самоидентичности обосновывается конструктивная роль инициативы и поддержки другого человека, а также роль самой личности, в создании Я-нарратива, обновляющего Я-концепцию (Breen et al., 2013).

В исследованиях Я, самоидентичности и Я-концепции вводятся понятия «Другой» и «отношения с Другим» как способствующие раскрытию закономерностей, состоящих, например, в соотношении «концепции значимого Другого» и Я-концепции, во включении «Другого» в Я-концепцию, во влиянии тревоги и избегания близости в интерсубъективном пространстве на снижение ясности Я-концепции личности, на понижение уровня самораскрытия, а также доверия к оценке Другого. Или, например, в наложении, перекрытии Я-концепции и концепции «Другого» при вовлечении личностью близкого человека в построение своей самоидентичности. Или в расширении Я-концепции при росте числа диалогических Я-позиций личности в контексте романтических отношений с Другим (Aron et al., 1991; Aron, Aron, 1995; Gurung et al., 2001; Mashek et al., 2003).

Предлагаются новые «фокусы» изучения диалогического $Я$ (Hermans, 2001), связывающие его генез с диалогичными отношениями Я не только к себе и к Другому, но и к множеству социальных и природных объектов 
(Konopka et al., 2018). Развивается «топологический» подход к диалогическому Я с использованием метафор, определяющих его как «ландшафт» или «пространственно-временную матрицу» внешних и внутренних Я-позиций личности, направленных к Другому, к себе и к миру во множестве их реальных образующих (Brinkmann, 2008; Raggatt, 2014; Marková, Novaes, 2020).

При разработке методологии изучения человека, включая индивидуальное Я и становление его самоидентичности, обосновываются перспективы, ограничения, возможности синтеза герменевтического, феноменологического и рефлексивного подходов, отвечающих современным парадигмам понимания и интерпретации, экзистенциального постижения и самопознания личности (Ginev, 2009, 2012, 2013, 2014).

Следуя персонологическим установкам в построении исследования и придерживаясь новых эпистемологических парадигм в науках о личности, мы разработали ряд взаимно раскрывающих и уточняющих моделей самотождества Я, достигаемого на основе процессов отождествления и разотождествления с собой, опосредованных значимым Другим. Модели стали результатом применения метода герменевтики философско-психологических и художественных текстов, выбранных в связи с их наибольшей релевантностью замыслу работы.

Моделирование на основе герменевтики было нацелено, во-первых, на концептуальный синтез онтопсихологических идей о Я и его отношениях, представленных в размышлениях С.Л. Рубинштейна о бытии человека в мире (Рубинштейн, 1973), а также идей экзистенциального осмысления со-бытия личности с Другим Ж.-П. Сартра (Сартр, 2002). Соединение в конщептуальном подходе взглядов этих, казалось бы, «несоединимых» исследователей прием, позволяющий воссоздать и развить опыт выдающихся ученых в раскрытии феноменов, попавших в центр внимания современных психологов и требующих, с одной стороны, актуализации классической мысли, с другой продвижения мысли в актуальном научном контексте.

Во-вторых, моделирование было сориентировано на культурно-феноменологическую конкретизацию концептуального подхода к изучению условий и парадоксов достижения самотождества Я в аспекте отождествления-разотождествления с собой. Решению этой задачи могла способствовать герменевтика художественного текста, созданного на основе уникального самопознания автором своей жизни с акцентами на историю Я-героя. Таким автором в нашем исследовании стал И. Бунин (2004). Взаимовложение результатов концептуального и феноменологического анализа и синтеза позволило разработать рефлексивно-диалогическую модель достижения самотождества путем отождествления-разотождествления Я с собой.

В-третьих, построение моделей послужило цели эмпирического изучения процессов отождествления-разотождествления с собой в рефлексивном движении к самотождеству, взятому в аспекте такого важнейшего для становления Я качества, как открытость опыту. Инструментом эмпирического исследования стало рефлексивное интервъю, вопросы которого должны были конституировать внутренний диалог со значимым Другим и актуализацию процессов отождествления и разотождествления Я с собой как реальным или 
потенциальным обладателем качества «открытости опыту» в составе Я-концепции. Прогноз результатов эмпирического исследования предполагал выявление индивидуальных конфигураций процессов отождествления и разотождествления с собой посредством значимого Другого и определение на основе обобщения данных конфигураций форм самотождества Я, характеризующихся разной степенью разрешения парадокса обретения и утраты тождества с собой.

\section{Концептуальная модель отождествления-разотождествления Я с собой}

Концептуальная модель построена как континуум положений, содержания которых раскрывают ведущие категории и способ реализации замысла исследования.

1. При изучении процессов достижения самотождества принципиальным является определение Я в качестве реального человека, конкретной личности, проживающей телесную, психическую и деятельную жизнь в мире. «Я - это не сознание, не психический субъект, а человек, обладающий сознанием, наделенный сознанием, точнее, человек как сознательное существо, осознающий мир, других людей, самого себя» (Рубинштейн, 1973, с. 335). Находясь и действуя в мире, Я противополагает себя вещам, к которым причастно, своим предметным действиям, другим людям, самому себе. «Я-в-мире» в каждый момент своей деятельной жизни становится объектом для Я-субъекта.

Я выступает субъектом, имеющим предметом самого себя, обладает нераздельной субъект-объектной сущностью. Мир во множестве своих образующих является «проявителем» возможностей, присущих действующему телесно-психическому Я, заключает множество «обещаний» для субъекта. «Мир как коррелят возможностей, которыми я являюсь, появляется в момент моего возникновения как огромный эскиз моих возможных действий» (Сартр, 2002, с. 342).

Я - упорядоченность мира для самого себя; самосознание собственных жизненных возможностей в перспективе их реализации; неизвестность себя в прошлом, настоящем и будущем, ожидание и полагание себя «в потенциале»; единство себя во времени: присутствие по отношению к себе, вспоминание себя и ожидание себя; ощущение и чувство, понимание и интуиция своей самотождественности.

Субъект-объектное пребывание и активность Я во внешнем и внутреннем мире состоят в непрерывной смене и переходе процессов отождествления разотождествления - нового отождествления с собой как динамичной связи в-себе (Я-субъекта) и для-себя (Я-объекта) в направлении единства «в-себедля-себя» (Сартр, 2002). Указанная связь может устанавливаться в форме самосознания, отношения, деятельности, творчества, рефлексии и означает перевод Я себя к своим собственным возможностям. При этом лишь рефлексивное сознание Я имеет объектом себя непосредственно. Единство в-себедля-себя определяет достижение самотождества Я.

2. «Человек и мир суть относительно существующие, и принципом их бытия является отношение» (Рубинштейн, 1973, с. 328). Отношение является 
одним из ведущих способов человеческого существования в мире, входит в структуру человеческого бытия, составляет объективное свойство Я. Для Я «относиться» - это вовлечь другое в свое бытие, привести к собственным возможностям, актуализировать свои потенциалы, проектировать себя-в-будущем, воплотиться в другом. «Другое» вызывает и испытывает отношение себе, становясь значимостью для Я. Появление значимости в жизни личности порождает активность ее переживания и самопознания, приводит в действие, по выражению Ж.-П. Сартра, «очарованную рефлексию». Любое развивающееся отношение, имея в структуре рефлексию, предполагает включение в себя самоотношения личности. По сути, встать в любое отношение - значит «противополагать себя себе самому» (Там же, с. 334), иметь интенцию к разотождествлению Я с собой, взаимодействующим с объектом отношения, быть готовым к преобразованию себя объектом и к самопреобразованию, а затем к отождествлению с собой на основе своих субъектных вкладов и отражений в объекте и самом себе.

Я во всех его осознанных изменениях конституируется в любых отношениях, особенно в отношении к значимому другому человеку, дающему Я новые пространства существования в своем внешнем и внутреннем бытии. Я «не может быть раскрыто только в отношении к самому себе, обособленно от отношения к другим людям (другим конкретным “я”)» (Там же, с. 337). Другой человек является необходимым условием существования Я, которое «обусловливает, детерминирует меня и имплицитно дано, наличествует во мне» (Там же, с. 360).

3. Другой человек, или «Другой», является в бытии личности таким же Я, как и она сама. «Мое Я - это “мое Я" каждого человека, каждого Я... "Я" всеобщность, свойственная всем, отношение к которой определяется отношением каждого Я к другим людям» (Там же, с. 335). «Другой» является для Я реальным «синтетическим единством своих опытов»: выражения лица, мимики, жеста, действий, поступков, высказываний. Получая этот опыт в отношении к Другому, Я расширяет свое самотождество, приобретая возможность искать и обнаруживать Я-неизвестное, по-новому организовать свой собственный опыт, восполняя его приобретениями, полученными от Другого, и транслируя другому Я свой обновленный образ и активность.

Я в отношении $\kappa$ Другому является субъектом и испытывает действие субъектности другого Я, являясь объектом для этого Я и полагая его объектом для себя. «Мое отношение, отношение данного моего “я” к другому “я” опосредствовано его отношением ко мне как объекту, то есть мое бытие как субъекта для меня самого опосредовано, обусловлено, имеет своей необходимой предпосылкой мое бытие как объекта для другого» (Там же). В смене субъектобъектных позиций Я и Другого Я оказывается воздействующим на Другого, представленным в нем, преобразованным в его внутреннем мире, внутренне встречающим Другого со своим присутствием в нем и в свою очередь проектирующим его преобразования. «Мы бесконечно отсылаемся от Другого-объекта к Другому-субъекту и обратно; ход никогда не останавливается, и именно этот ход, с его быстрыми изменениями направления, конституирует наше отношение к Другому» (Там же, с. 421). Этот ход, совершаемый рефлексивно, 
позволяет Я найти себя в Другом-субъекте, воссоздать собой субъектность Другого, реализовать собственную субъектность, овладевая Другим-объектом, и возвратиться к в-себе и в мир, становясь, благодаря сделанным рефлексивным шагам, основанием самого себя. Другой, таким образом, является возможностью Я, «неизбежным посредником, соединяющим меня с самим собой... Другой нужен, чтобы Я могло основать себя» (Там же, с. 246). Находя себя в реальном взаимодействии с Другим, обнаруживая себя в бытии Другого, открыв свои изменения, произведенные Другим, Я отрицает себяналичного или разотождествляется с собой. Принимая свое другое Я, признавая его бытие в мире частью себя и вбирая в себя образы взаимной внутренней представленности с Другим, Я отождествляется с собой, продвигаясь в самотождестве и способности быть основой себя. Непрерывно разотождествляясь-отождествляясь с собой посредством значимого Другого, Я парадоксально продвигается в своем самотождестве.

4. Рефлексивная реализация отношения Я - Другой, или, иначе, внутренний диалог Я с Другим, имеет ряд «измерений». В этом диалоге рефлексия, соединяясь с переживанием и действием, осваивает пространства, конституирующие реальное взаимодействие Я и Другого (измерение между-Я-иДругим), присутствие Я во внутреннем мире Другого (измерение Я-вДругом), бытие Другого во внутреннем мире Я (измерение Другой-в-Я), относительно автономное существование Я-сам (измерение Я-в-себе) и позиционирование отношения «Я - Другой» в окружающем мире (измерение Яв-мире-с-Другим). Широкий спектр измерений отношения «Я - Другой» и их структурная организация создают многие возможности для Я «укрепиться» в себе, познавать себя, встретиться с Я-неизвестным и открыться для преобразований в каждом из измерений и их структуре в целом.

\section{Измерение Между-Я-и-Другим}

Здесь отношение «Я - Другой» реализуется в конкретной ситуащии, общей для обоих субъектов, где Другой проявляет себя в своей значимости для Я, совершает действия, актуализирующие возможности Я, и встречает ответную деятельность, раскрывающую его собственный потенциал. Бытие Я и Другого совершенно реально, это жизнь конкретных личностей, «бытие как условие моей самости напротив Другого и самости Другого напротив меня. Это мое внешнее-бытие: не бытие, переносимое вовнутрь, которое пришло бы извне, но нечто внешнее, взятое и признанное как мое внешнее» (Сартр, 2002, c. 307). В ситуации Я и Другой выступают в качестве фокусов, центров, вокруг которых организуются миры каждого из них.

Личность в отношении к Другому может создать условия для таких воздействий и вкладов Другого и для такой собственной активности, что ее знаемое для-себя путем отождествления с ним становится новым аспектом в-себе. Или же не становится, отрицаясь Я как случайное и чуждое ему. Возможно также расширение области Я-неизвестного, принимаемого или не принимаемого Я в качестве части себя и потенциального предмета самопознания. 
Движение к новому самотождеству Я в конкретной ситуации с участием Другого инициируется освоением вещей посредством совместных действий, реализацией телесных способностей Я и Другого, высказываниями обоих в диалоге, силой взаимных взглядов. Если, например, Я и другой человек смотрят друг на друга, «это значит, что Я внезапно затронуто в своем бытии и что существенные изменения появляются в его структуре, изменения, которые Я может постичь и концептуально фиксировать рефлексивным cogito» (Там же, с. 363).

\section{Измерение Я-в-Другом}

В данном измерении Я выступает одним из образных, эмоциональных и мыслительных содержаний внутреннего мира Другого. Другой конституирует Я «по новому типу бытия», благодаря чему Я приобретает свою новую объектность, новое для-себя, к которому может встать в отношение. Открыв этот тип бытия, Я оказывается сначала вне своего действия, отношения и познания, не знает, ни каким является, ни каково его место в мире Другого, ни какой стороной мир, где Я находится, обращен к Другому (Сартр, 2002). Далее неопределенное «в-Другом» рефлексивно превращается в для-себя, и Я в акте разотождествления с собой раскрывает, каким является для Другого и действительно ли это Я.

Разотождествляясь с собой, Я может признать, что представление Другого о нем истинно и открывает ему ранее неизвестные стороны себя, с которыми он может отождествиться. Этапы позитивной динамики самотождества, которые Я проходит, оказываясь в данном измерении, Ж.-П. Сартр определяет следующим образом: Я и Другой абстрактны, индивидуальны, противоположны друг другу; Я проживает абстрактный момент тождества с собой; Я обнаруживает свою индивидуальность в Другом как внешний чувственный и мыслимый объект; Я открывается себе как личное присутствие в Другом; рефлексивное когито бросает Я-в-Другом к в-себе, обеспечивая новый прорыв Я к самотождеству (Там же, с. 247). Вместе с тем рефлексивное отношение Я к своему бытию-в-Другом может вести к дальнейшему разотождествлению $c$ собой, если в Другом представлен Я-объект с неузнаваемыми свойствами и качествами или «иностранец», которого Я не желает брать, возвращаясь к всебе. В направлении же к достижению нового самотождества «Другой, на точку зрения которого о себе Я встает, превращается в его собственную возможность; Я признает свое воспринимаемое Другим бытие для-себя и хочет отождествиться со свободой Другого как основывающей его бытие в-себе» (Там же, с. 379).

\section{Измерение Другой-в-Я}

Значимый Другой несет в себе потенциальную субъектность Я с первой встречи, так как, обращаясь к Я различными сторонами своей личности, вызывает его к актуализации разнообразных возможностей и к активному самовыражению. В пространстве внутренней, рефлексивной активности Я 
«Другой» предстает объектом в открытости к непосредственному постижению Я-субъектом и в сокрытии многих тайн своего внутреннего мира, одной из которых является Я-объект-в-Другом с его незнаемыми свойствами и жизненным миром. В рефлексии «Другой дается мне как конкретное и очевидное присутствие, которое я ни в коем случае не могу извлечь из себя и которое вовсе не может быть поставлено под сомнение и стать объектом феноменологической редукции или всякого другого эпохе» (Сартр, 2002, с. 294).

Внутреннее бытие Я включает в себя отраженное бытие и свойства Другого, рефлексивные представления Я о влияниях и вкладах Другого и о его сущности, невидимой для многих других людей, так как Я имеет о Другом неповторимый опыт. Одновременно бытие Я включает осознание соотношения автономии Другого и его воплощенности в Я. Важная часть внутренней жизни Я является его бытием в отношении к Другому и в качестве «Другого», т.е. Я во взаимодействии с внутренним Другим, становясь для-себя и разотождествляясь с собой в пользу единения с Другим, может в результате последующего акта отождествления обогатить свое самотождество возможностями Другого.

\section{Измерение Я-в-себе}

Существование Я, включая рефлексивный план, выступает как внешняя и внутренняя причинность «Другого», в том числе значимого человека, к которому Я встает в отношение. Эта причинность предполагает переход Я в «другое» и обогащающий возврат к в-себе, а также «идеальное, интенциональное проектирование себя как характерное для существования, внутрь которого включено самосознание» (Рубинштейн, 1973, с. 357). Переживание и осознание Я-в-себе с содержащимся в его структуре «проектом себя» определяет установившееся самотождество Я с его тенденцией к изменению и развитию при реализации проекта и встрече личности с обновленным Я. «В-себе», становящееся в направлении к самотождеству, проходит, согласно концепции Сартра, ряд преобразований: возникновение «чистого тождества с самим собой» характерное для раннего периода жизни человека; разделение «в-себе» и для-себя, когда собственное существование выступает для Я независимым объектом; выражение Я в своем действительном, внешнем бытии, предстающим для Я очевидностью, подтверждающей, что «Я есть Я»; открытие себя как объекта для других Я; «признание Я себя в других самосознаниях тождественным с ними и с собой» (Сартр, 2002, с. 259), т.е. проходит процесс достижения самотождества посредством Другого.

Ставшее Я-в-себе имеет относительно автономное существование, рефлексивно обогатившись осознанием своей продуктивности и диалогичности в мире, своей возвращенной себе данностью и субъектностью в мире Другого, а также данностью и субъектностью Другого в собственном мире, осознанием своих открытий Я-неизвестного. Такое «исполненное Я» обладает зрелостью, силой и свободой в обращении с собой в плане освоения и приведения к своим возможностям раскрывшейся реальности и потенциальности мира, других, значимого другого, самого себя. 
Особое значение приобретает для зрелого Я его позиционирование в мире в качестве имеющего уникальный опыт отношения к Другому. Я-в-мире-сДругим стремится превратить себя в такой объект, к которому устремляются признание и интенции к идентичности многих людей, а фактичность взаимодействия Я и Другого становится объективным событием во множестве жизненных миров. Когда мир и другие способствуют личности в «овнутрении» объективных следов своего единства с Другим, она может совершить мощный прорыв в самотождестве Я.

5. В измерениях отношения Я к Другому с включенным в него отношением к себе реализуются акты разотождествления и отождествления с собой, динамика и организация которых определяет различные формы самотождества Я. Выделение данных форм, на наш взгляд, представляет интереснейший предмет теоретических и эмпирических исследований.

Основой процессов отождествления-разотождествления с собой являются субъект-объектная сущность Я и существование Я в ипостасях «в-себе» и «для себя». Отождествление и разотождествление Я с собой в отношении к Другому и в рефлексивном диалоге с Другим имеют объектами различные аспекты Я: его телесные свойства, личностные черты и качества, способности, действия, состояния, психические процессы, отношения и их различные измерения, пребывание в разных местах, положениях, временах. Уровень развития, ценностные характеристики, степень выраженности этих объектов в длясебя, рефлексивно полагаемая и предполагаемая данность объектов Другому, а также частота, эффекты и соотношение актов отождествления и разотождествления с тем или иным аспектом Я, исходящих от в-себе, конституируют результаты достижения - недостижения самотождества Я.

Разотождествление-отождествление с собой может происходить, когда:

- Я обнаруживает свою телесную активность во внешнем мире;

- Я находит свою запечатленность в предметном мире;

- Я встает в отношение к себе и в отношение к Другому;

- Я видит и сознает себя взаимодействующим с Другим в мире;

- Я находит свою представленность и активность в-Другом;

- Я открывает себя как воплотившего Другого в образе, его влияниях и вкладах;

- Я улавливает «коллективный взгляд» в мире на свое со-бытие с Другим и на свое отношение к нему;

- Я осознает постоянство своих свойств и появление нового в самом себе;

- Я обнаруживает Я-неизвестное в себе, своих действиях и отношениях;

- Я создает проект себя, предназначенный для реализации в своей предстоящей жизни;

- Я открывает себя в перспективе завершения жизни.

В процессах отождествления и разотождествления с собой Я устанавливает совпадение - несовпадение с собой, знание - незнание себя, а также принимает - отрицает себя, испытывает согласие - несогласие с собой, приближает - отчуждает себя, утверждает тождество с собой - отличие от себя, постигает гармонию - противоречие с собой. 
6. Рефлексия в контексте отношения и диалога «Я - Другой» может иметь несколько основных «фокусов» Я-репрезентаций: Я в каждом из измерений отношения; Я в различных измерениях отношения, данное самому себе, или для-Я; Я в различных измерениях отношения, выступающее в идентификации с Другим и рефлексивно данное для-Другого. Таким образом, Я как объект активности Я-субъекта приобретает в этой «рефлексии разных порядков» тот объем, который существенно расширяет основания самотождества Я в отношении к Другому и посредством Другого.

Концептуальное обоснование отождествления-разотождествления Я с собой посредством Другого может найти преломление, уточнение и конкретизацию при обращении к художественно-литературным текстам и герменевтической экспликации из них содержаний и смыслов, касающихся исследуемых феноменов.

\section{Культурно-феноменологическая модель отождествления-разотождествления Я с собой}

Материалом герменевтического анализа стало произведение И.А. Бунина «Жизнь Арсеньева», имеющее автобиографический характер (Бунин, 2004). Воспользовавшись системой идей концептуальной модели, мы разделили проинтерпретированные результаты рефлексии автора на категории, соответствующие феноменам самотождества Я, Я-неизвестного, а также феноменам отождествления и разотождествления с собой, обнаруженным в различных измерениях отношений Я к себе, другим, Другому.

\section{Самотождество Я (в-себе-для-себя)}

Я - одиночество в мире наедине с одинокой звездой; Я - привлекательное, нравящееся себе в зеркале лицо; Я - мой наилучший образ для себя в своей красоте, силе и ловкости; Я - обладающий отцовскими чертами, которые люблю у него; Я - навсегда захваченный любовью матери; Я - наследовавший впечатлительность от предков из русского просвещенного общества; Я - имеющий таинственное сродство с далеким европейским рыцарским прошлым; Я - душевное слияние с православной церковной службой; Я - чувство кровного родства с Россией; Я - проблеск сладостного чувства любви; Я - мои встречи с музой и радость «всех впечатлений бытия»; Я - мое чувство кровной принадлежности к великим русским поэтам; Я - мой поэтический дар; Я - бедность с мечтой о своей полной блеска, совершенной жизни; Я - писательский успех и полнота себя в этом; Я - любовь ко всему в этом мире; Я - полнота своей осуществившейся мечты; Я - любовь к Лике во всех ее радостях и муках; Я - мои впечатления, видящий себя в них и сохраняющий их как новые части себя-писателя; Я человек, взрослеющий в самосознании своего роста и развития, в своем взгляде «над» собой и окружением; Я - желание любить, сохраняя свободу и превосходство; Я - достойный в любви владеть жизнью другого; Я - мои тяжелые воспоминания, «навязчиво помнящий»; Я - чувство «гибельного одиночества». 


\section{Разотождествление Я с собой-в-себе}

Я - иное Я, способное отрешиться от текущей жизни, взглянуть на все из «неземной дали»; Я - не тот, кто не может расстаться с собой и своей прошлой жизнью; Я - не то Я, которое желает помнить свою юность: «Был ли я на самом деле?»; Я - не тот автор, который может писать о том, чего сам не знал в своей жизни; Я - не тот, кто мирится со своими навязчивыми мыслями и воспоминаниями; Я - другое Я, чем то, что находится здесь, среди чужих людей, в чужом городе; Я - другой, устремляющийся к своим представлениям в представляемом мире.

\section{Между-Я-и-Другим}

Отождествление с собой: Я - мое превосходство над Ликой, мое право на ее свободу и самоотдачу мне; Я - достойный во взаимоотношениях с Ликой владеть ее жизнью; Я - чувство неблагополучия, потери близости во взаимоотношениях с Ликой.

\section{Я-в-Другом}

Отождествление с собой: Я - убеждение отца о моем призвании поэта; Я представления отца о моих тонких чувствах и уязвимости, о моем «несвоевременном сердце», «прекрасной душе»; Я - нелестное мнение отца обо мне; Я отцовское тревожное видение меня и моего будущего; Я - предчувствие Лики о неразрешимости противоречий во мне.

Разотождествление с собой: Я - не тот, кто существует в представлениях брата о моем будущем; Я - не такой, каким меня представляет Лика в моем отношении к ней; Я - не тот, кто дал повод Лике расстаться со мной из-за моей «нелюбви» к ней; Я - чужой себе в своих зеркальных отражениях в других людях.

\section{Другой-в-Я}

Отождествление с собой: Я - дорогой мне образ отца с его близкими мне качествами и противоречиями; Я - образ моей любимой матери и страдание за нее; Я - переживание неизвестности для меня моего отца, неразгаданности тайны его души; Я - любимый образ Лики, приходящий ко мне во сне; Я чувство отчуждения Лики в нашей совместной жизни.

Разотождествление с собой: Я - не тот, кто может испытывать боль по поводу благополучия юности отца и его неспособности дать мне то же; Я - не тот, кто тяжело переживает закрытость отца; Я - иной, чем тот, кто может чувствовать ревность и стыд из-за поведения Лики.

\section{Я-неизвестное}

Я - забывший то о себе, что знал сразу после рождения и что незримо есть во мне; Я - плененный тем загадочным в сказках, что может мне рассказать 
обо мне; Я - неизвестный себе в самой сути своей жизни и в ее перспективе; Я - стремящийся в неизвестные пространства жизни, где чувствуется мое отсутствие; Я - знающий свое незнание о своей жизни, согласный с Л. Толстым, что «ничего нет в жизни, кроме ничтожества всего понятного мне, и величия чего-то непонятного, но важнейшего для меня...»

Соединяя результаты культурно-феноменологического и концептуального моделирования (по сути, «идеи» тоже выступают культурными феноменами Старовойтенко, 2019), сделаем «сборку» актов отождествления и разотождествления Я с собой, акцентируя при этом эмоциональные, образные, мыслительные, интуитивные, сигнификативные и основанные на психическом синтезе способы обращения Я с собой, включенные в процессы рефлексии.

\section{Отождествление Я с собой}

Означение Я себя знаком «Я»; знание Я-субъекта о своем совпадении с собой как живущим во внешнем и внутреннем мире; переживание Я уверенности в себе, аутентичности себе, принятия себя, ценности и целостности себя; ощущение устойчивости себя в границах ситуации, тела, души, действия; мысленное самоотделение Я от других и Другого в своих особенных телесных, психических и практических качествах; противопоставление своего Я другим Я; постижение своего жизненного предназначения; чувство принадлежности себе всего, что Я может, хочет, проживает, реализует, использует, создает; признание Я своих новых свойств, качеств, умений, особенностей поведения; узнавание Я себя в изображениях, зеркалах, отражении в-других. самонаблюдении; чувство совпадения Я с собой в автопортретах и Я-нарративах; принятие Я образа себя, созданного и выраженного Другим; познание Я значимых для себя качеств, состояний, действий Другого; принятие Я собственного отсутствия или неизвестности себя во внутреннем мире Другого; создание идеала Я, или «наилучшего Я», побуждающего к отстаиванию и развитию себя; пережсивание Я своего сродства великим людям в их творческом самовыражении; запоминание Я собственных ощущений, представлений и мыслей о себе, поддерживающих его аутентичность; переживание Я уникальности себя, своей единственности среди других людей; знание себя в том, что создано Я в мире, что стало вкладом в жизнь других людей; обобщение в Я-концепцию множества своих знаемых качеств и отраженных образов себя, родившихся в сознании и артикулированных многими другими людьми; знание о существовании Я-неизвестного и включение этого аспекта себя в Я-концепцию; мысленное определение и принятие Я своих противоречий; создание Я рефлексивной истории своей жизни и себя в ее контексте; чувство непрерывности себя во временно́й транспективе; переживание Я бесконечности себя в бытии за границами личного существования; проектирование Я своих возможностей-невозможностей в обращении к будущему; чувство принадлежности Я самому себе.

\section{Разотождествление Я с собой}

Означение Я себя как «не-Я», «мое другое Я»; переживание Я как «чужого себе» при включении в чуждый мир, круг посторонних людей; отрищание Я 
своих субъективно нежелательных состояний, качеств, способов действий; чувство отчуждения Я от самого себя; мысленная постановка Я задачи развития у себя новых качеств, способностей, деятельностей, требующей ухода от себя; чувство отторжения Я своих слабостей, несостоятельности, неуспешности; переживание Я неразрешимости своих противоречий; интуитивное «расставание» Я со своими устойчивыми представлениями о себе; неприятие Я ощущения и идеи присутствия в себе Я-неизвестного; переживание несогласия с «собой», отраженным значимым Другим, отказ от свойств, «видимых» в Я другим человеком; присвоение себе свойств значимого Другого, субъективное движение к «новому Я»; понимание Я внутреннего присутствия «чужого Я», противоречия своего и несвоего в себе; мысленное заимствование нового образа Я из культуры и мира социальных образцов; чувство потери своей связи с Самостью; интуищия «Абсолютного Я» как ориентира самопреобразований в настоящем и будущем; переживание тайны исчезновения себя вместе с ушедшим из жизни Другим; чувство «лживости зеркала» как несовпадения образа Я в Другом с собственными представлениями о себе; неузнавание Я в себе того, кого видит в нем Другой; отвержение Я эмоций, вызываемых им у Другого; чувство недовольства Я собой в связи со своей представленностью в других людях; отрицание Я в себе ребенка, подростка, юноши как своих «отживших» сущностей; сомнение Я в собственном бытии в прошлом: «был ли я?», «это был я?»; незнание Я смысла своего существования при взгляде в будущее; предчувствие себя-неизвестного в своем отдаленном будущем; забывание себя в своей прошлой жизни; переживание Я собственного отсутствия в оставленных местах жизни; интуиция Я собственного отсутствия во внутреннем мире Другого; сомнение Я в своей принадлежности самому себе: «этот я - скорее для других, чем для себя»; представление о себе, направленное на Я, еще не существующее, иное, чем сейчас; исключение Я нежелательных воспоминаний или навязчивых мыслей о себе; постижение Я себя как незнакомца, постороннего, недоброжелателя, врага или, напротив, нового друга и помощника; переживание Я утраты себя при забывании его значимым Другим; решение Я об изменении тех или иных аспектов себя и своей жизни.

За концептуальным и культурно-феноменологическим моделированием последовала разработка рефлексивно-диалогической модели отождествленияразотождествления Я с собой как «руководства» для формулировки вопросов интервъю, составивших содержание инструментария эмпирического исследования.

\section{Рефлексивно-диалогическая модель отождествления-разотождествления с собой при достижении самотождества Я}

В модели представлен ряд исследовательских позиций, позволивших разработать континуум вопросов интервью, актуализирующих рефлексию респондента в контексте внутреннего диалога со значимым Другим по поводу обладания интервьюируемым определенным личностным качеством. 
Характер вопросов направляет рефлексию к отождествлению-разотождествлению Я с собой в различных измерениях отношения к Другому.

Позиции, ориентированные на эмпирическое исследование методом интервью, состоят в следующем.

1. Выделяются рефлексивные измерения отношения «Я - Другой», в которых возможны акты отождествления-разотождествления Я с собой: МеждуЯ-и-Другим-для-Я; Я-в-Другом-для-Я; Другой-в-Я-для-Я; Я-в-себе-для-Я; Яв-мире-с-Другим-для-Я; Между-Я-и-Другим-для-Другого; Я-в-Другом-дляДругого; Другой-в-Я-для-Другого; Я-в-себе-для-Другого; Я-в-мире-с-Другимдля-Другого.

2. Рефлексия в различных измерениях отношения «Я - Другой» рассматривается как конституируемая Я-репрезентациями личности.

3. Личностным качеством как объектом рефлексии и предметом Я-репрезентаций субъекта выступает «открытость опьту», существенно определяющая активность взаимодействия Я с миром, с другими людьми, с собой. Под «открытостью опыту», в соответствии с существующими определениями, понимается в познавательном плане потребность в поиске знания и незнания, склонность к новизне, гибкость мышления, любознательность, живость воображения, открытость впечатлениям, несогласие с общепринятыми представлениями; в эмоциональном плане - глубина переживаний, познание своих чувств; в культурном плане - любовь к культуре, эстетическая чувствительность.

4. При анализе рефлексивного диалога по поводу качества открытости опыту учитываются: полнота рефлексивного охвата измерений диалога; содержания Я-репрезентаций в различных измерениях диалога; наличиеотсутствие Я-репрезентаций в разных измерениях; доступность-недоступность, активность-пассивность рефлексии в фокусах для-Я и для-Другого; сходство-различие-противоположность содержаний Я-репрезентаций в различных измерениях диалога; осознанность-неосознанность противоречий между Я-репрезентациями в разных измерениях; акценты на субъективно позитивные или негативные аспекты рефлексируемого качества в различных измерениях; соотношение в содержании Я-репрезентаций в разных измерениях осознанного знания-незнания о себе; выраженность или невыраженность интенции к синтезу Я-репрезентаций в целостное «Я, открытое опыту» или в Я, имеющее самотождество в аспекте открытости опыту.

5. При интерпретации результатов рефлексии во внутреннем диалоге Я Другой выделяются акть отождествления и разотождествления Я с собой в различных измерениях данного диалога в фокусах для-Я и для-Другого. Проясняется, происходит ли отождествление-разотождествление Я с открытостью опыту в реальном взаимодействии с Другим; отождествление-разотождествление с представлением Другого о наличии или отсутствии у Я данного качества; отождествление-разотождествление с «Другим» как обладающим или не обладающим данным качеством или стимулирующим либо не стимулирующим у Я его развитие; отождествление-разотождествление Я с собой как обладающим данным качеством и развивающим его у себя; отождествление- 
разотождествление Я с собой как проявляющим данное качество во взаимодействии с Другим и меняющим, благодаря этому, что-то в мире и окружении; отождествление-разотождествление с Я-неизвестным, обнаруженным Я во внутреннем диалоге о своей открытости опыту.

6. Важным моментом интерпретации результатов рефлексивного диалога является определение динамичной конфигурации актов отождествленияразотождествления Я с собой посредством Другого в аспекте своей открытости опыту (ОО). Основными параметрами конфигурации выступают: содержания репрезентаций (указывающие на смысловое богатство-ограниченность освоения и реализации ОО); преобладание актов отождествления или разотождествления Я с собой в рефлексивном диалоге; полнота рефлексивного охвата измерений диалога; единство или противоречия Я-репрезентаций в различных измерениях диалога; обнаружение и принятие Я-неизвестного в рефлексивном диалоге. Та или иная конфигурация образует определенную форму самотождества Я, разрешающую или не разрешающую парадокс взаимной необходимости процессов отождествления и разотождествления с собой на пути достижении Я единства с собой как в целом, так и в своих отдельных образующих.

\section{Методика рефлексивного интервью и результаты ее применения}

Рефлексивно-диалогическая модель составила основу для разработки континуума вопросов интервью, направленных на самопознание личности в различных измерениях отношения «Я - Другой». Созданная рефлексивная методика была применена в эмпирическом исследовании, проведенном под нашим руководством магистром психологии А.В. Ерымовской на выборке 40 респондентов (студентов и лиц с высшим образованием). Приведем полученную форму интервью с ответами одного из респондентов и их интерпретацией, состоящей в выявлении актов отождествления и разотождествления Я с собой:

1. Респонденту сообщается, что ему предлагается возможность внутренне обратиться к себе и другому человеку по поводу личностного качества «открытость опыту».

Респондент: $O$, это очень важное качество в людях для меня. (Идентификаџия Я с ОО как человеческим качеством.)

2. Респондента знакомят с основными значениями понятия «открытость опыту». Респонденту также сообщается, что человеку может быть присуща открытость опыту как в совокупности ее образующих, так и в отдельных из них.

3. Респондента спрашивают, насколько значимо для него качество открытости опыту у других людей.

Респондент: Очень значимо. Мне кажется важным новаторство, очень откликается. Мне кажется, у меня с этим есть проблема: в моей жизни мало людей, которые со мной в этом совпадают. Например, в отношениях с молодьмм человеком. У него нет тяги к переменам и новым впечатлениям. Да, мне кажется 
это важным и в работе, и в жизни. (Разотождествление Я с другими, не имеющими качества ОО.)

4. Респондента спрашивают, насколько значима для него открытость опыту как качество, которое может быть присуще ему самому.

Респондент: Мне кажется важным, что у меня есть это качество, но местами оно усложняет жизнь. Например, потребность в новых впечатлениях. Ее довольно сложно вписать в стабильные отношения, если возникает ситуащия, знаешь, полежать на диване и ничего не делать. Для большинства людей это ок, а меня начинает «клинить», начинаются конфликть. Еще, например, сейчас у меня не самый благополучный период в жизни, и я стараюсь экономить. Иу у меня есть чувство, что если я не увижу что-то новое, то лето упущено. И я психую, что нет денег на отдьх. Я понимаю, что это иррационально, но на эмоциональном уровне меня очень коробит, и так часто происходит. (Отождествление Я с собой в аспекте ОО с указанием на противоречия отождествления.)

5. Респонденту предлагается мысленно выбрать высокозначимого для него Другого и вступить во внутреннее общение с ним. Значимый Другой обозначается буквой $\mathrm{N}$.

6. Респонденту сообщается, что ему предстоит подумать и высказаться о том, насколько ему свойственна открытость опыту, на взгляд другого человека.

Респондент: Да, $N$ замечает, что мне это качество свойственно. Думаю, адекватно оченивает. (Отождествление Я с собой в аспекте ОО, в фокусе дляДругого.)

7. Затем респонденту ставится задача последовательно, развернуто ответить на следующие вопросы к себе:

- Присуща ли мне открытость опыту? В чем она более всего выражается?

Респондент: Да, несомненно. В открытости к знаниям и взглядам. Хотя нет, второе спорно. Еще в терпимости к впечатлениям, и к плохим, и к хороиим. (Отождествление Я с собой в аспекте ОО.)

- Насколько я неизвестен себе в плане своей открытости опыту? Что, на мой взгляд, мне неизвестно?

Респондент: Я думаю, не на 100 процентов себе известна. Прочентов на 80. Я Әумаю, что многое о себе знаю, но в зависимости от ситуации, думаю, могла бы многое неожиданное о себе узнать. А еще есть вещи, к которым я нетерпима, но ради другого человека могу их принимать. Думаю, мне неизвестно, до какой степени я могу сдвигать рамки. Думаю, иногда только обстоятельства могут показать, на что ты способен. (Отождествление Я с собой в плане принятия незнания о своей ОО.)

- Удается ли мне проявлять и развивать открытость опыту, когда я непосредственно общаюсь с N? Как это происходит?

Респондент: Скорее нет, чем да. Происходит столкновение взглядов. Часто, когда я просто выражаю свое мнение, завязывается спор, вместо того чтобы обсудить и остаться даже, например, каждому при своем мнении. Иногда какую-то часть моих проявлений $N$ не принимает. (Разотождествление $Я$ с собой в аспекте ОО, в измерении Между-Я-и-Другим.) 
- Удается ли мне, по мнению N, проявлять открытость опыту в непосредственном общении с ним? Что конкретно он говорит об этом?

Респондент: Средне. Ближе к нет, наверное. Некоторую часть моих таких проявлений не принимает. Но я думаю, что $N$ считает, что я могу проявлять открытость опыту в общении с ним. Иногда говорит, что я любознательна и у меня разумные взгляды на жизнь. (Разотождествление Я с собой в аспекте ОО, в измерении Между-Я-и-Другим. Намечена перспектива отождествления.)

- Являюсь ли я вообще в представлениях $\mathrm{N}$ человеком, открытым для опыта и активно приобретающим его? На чем я основываюсь в своем ответе?

Респондент: Да, сто процентов. Этот человек по отношению ко мне часто выступает как ведомый и говорит, что от меня перенимает знания. Я что-то осваиваю первой, и у меня этот человек что-то перенимает. Это приятно. (Отождествление Я с собой в аспекте ОО, в измерении Я-в-Другом.)

- Важен ли я для $\mathrm{N}$ как человек, открытый для опыта и активно приобретающий его? Говорит ли он что-либо об этом?

Респондент: Нет, не важна. Я думаю, что нет. Он ничего об этом не говорит, но я понимаю, что для этого человека важны другие качества. (Разотождествление Я с собой в аспекте ОО, измерении Я-в-Другом, фокусе для-Другого.)

- Является ли $\mathrm{N}$ для меня человеком, который побуждает и влияет на меня в плане развития и выражения моей открытости опыту? В чем именно состоят его влияния?

Респондент: Я думаю, да. В плане какого-то уравновешивания и дозревания взглядов. Но именно что-то очень новое $N$ для меня не открывает, зато позволяет сглаживать какие-то негативные проявления: что мне вечно надо кудато бежать, что мне плохо, если за день ничего не произошло. Раньще, представь себе, я страдала, если я не сделала ни одной новой фотографии за день. Я переживала, что не смогу вспомнить этот день. Если я хотя бы один день просидела дома, даже если мне понравилось и я хорошо отдохнула, я начинаю переживать, что день упущен. И вот эта моя сторона благодаря $N$ сглаживается. (Отождествление Я с собой в аспекте ОО, в измерении Другой-в-Я.)

- Знает ли $\mathrm{N}$, что он важен для меня в плане развития открытости опыту? Как я могу об этом судить?

Респондент: Нет, не знает. Хм, я сейчас поняла, что никогда об этом не думала и не говорила N. Только на негативную сторону обращала внимание. (Разотождествление Я с собой в аспекте ОО, в измерении Другой-в-Я, в фокусе для-Другого. Проблематизация своего разотождествления.)

- Осознаю ли я себя человеком, стремящимся к открытости опыту и способным самостоятельно развивать ее? Что я делаю для этого?

Респондент: Да, сто процентов. Общаюсь с очень разными людьми, которые много себе разрешают в плане отсутствия рамок. Ну знаешь, все эти установки: нельзя открывать бизнес сразу, нужно сначала поработать.... И мне интересно общаться с теми, кто стал успешен, возможно, вообще без образования. Я общаюсь с людьми, которые рамки разбивают, и это мне помогает. Еще я много учусь и путешествую. (Отождествление Я с собой в аспекте ОО.) 
- Является ли моя открытость опыту, на взгляд N, результатом моих собственных усилий? В чем состоят, по его мнению, эти усилия?

Респондент: Я думаю, да. В том же самом: учебе, путешествиях, общении. (Отождествление Я с собой в аспекте ОО, в фокусе для-Другого.)

- Замечаю ли я, что моя открытость опыту во взаимодействии с $\mathrm{N}$ что-то меняет в мире?

Респондент: Нет, не думаю. (Разотождествление Я с собой в аспекте ОО, в измерении Я-в-мире-с-Другим.)

- Замечает ли $\mathrm{N}$, что моя открытость опыту во взаимодействии с ним чтото меняет в мире?

Респондент: Не думала об этом. (Разотождествление Я с собой в аспекте ОО, в измерении Я-в-мире-с-Другим, в фокусе для-Другого.)

- Сейчас, когда я поразмышлял о своей открытости опыту и ее отражении в $\mathrm{N}$, чувствую ли я какие-то изменения в себе? Произошло что-то в моем осознании и оценке этого свойства? Что именно?

Респондент: Да, да! Правда, было очень полезно. Например, я ответила «нет» в вопросе «Знает ли $\mathrm{N}$, ито важен для меня в плане моего осмыслления своей открытости опыту..» И я поняла, что никогда об этом не говорила ему и никак это не поошряла. Я только постоянно критикую его меньшую открытость, чем у меня, а можно было бы приободрить. (Отождествление Я с собой в аспекте ОО. Намечена перспектива расширения самотождества Я.)

- Есть ли у меня трудности в связи с тем, что мне присуще свойство открытости опыту?

Респондент: Да. К сожалению, у моих близких в основном нет этого качества. Мой молодой человек - вообще самыий консервативный человек, которого я знаю. При этом, если человек более открытый, чем я, я от него устаю. Мне в семъе комфортно с более консервативными людьми, а на дальнем общении -c открытыми. Я сейчас поняла, что у меня как будто есть что-то вроде адреналиновой зависимости от открытости к опыту и близкие меня тормозят. Я очень рада, что мы это проговорили.

Но если бы можно было выбрать одно интуитивно, то я бы выбрала открытых людей. (Коллизия разотождествления-отождествления Я с собой в аспекте ОО. Намечена перспектива ее разрешения.)

- Что буду делать дальше в отношении к своей открытости опыту?

Респондент: Развивать. При осознании того, что не все обязаны со мной в этом совпадать. И, думаю, быть открытой людям, которые со мной в этом не совпадают. И думаю, что открытость опыту не должна зависеть от внешних факторов и поддержки других людей, я могу ее развивать сама. (Отождествление Я с собой с перспективой развития и расширения самотождества в аспекте OO.)

В результате анализа текстов интервью, проведенного с опорой на концептуальную, культурно-феноменологическую и рефлексивно-диалогическую модели, были выявлены формы самотождества, реализуемые в самопознании, сфокусированном на определенном личностном качестве как предмете отождествления-разотождествления Я с собой. Каждая форма конституируется, 
как отмечалось, конфигурацией актов отождествления и разотождествления с собой посредством Другого, имеющей выделенные выше параметры. К выявленным формам самотождества Я относятся:

Развивающееся самотождество: смысловое богатство освоения и реализации ОО; преобладание актов отождествления Я с собой в рефлексивном диалоге; близкий к полноте рефлексивный охват измерений диалога; единство и вместе с тем осознанные противоречия Я-репрезентаций в разных измерениях диалога; готовность к разрешению противоречий; обнаружение и принятие Я-неизвестного в рефлексивном диалоге.

Становящееся самотождество: некоторая ограниченность смыслового освоения и реализации ОО; заметное преобладание актов отождествления Я с собой в рефлексивном диалоге; тенденция к достижению полноты рефлексивного охвата измерений диалога; осознанность сходства и противоречий Ярепрезентаций в различных измерениях диалога.

Противоречивое самотождество: некоторая ограниченность смыслового освоения и реализации ОО; выраженность и актов отождествления, и актов разотождествления Я с собой; «выпадение» в рефлексии ряда измерений диалога; осознанность противоречий Я-репрезентаций в различных измерениях диалога; обнаружение Я-неизвестного в рефлексивном диалоге.

Ригидное самотождество: ограниченность смыслового освоения и реализации ОО; акты отождествления Я с собой в аспекте ОО; «выпадение» в рефлексии ряда измерений диалога; неосознанность выраженных противоречий Я-репрезентаций в различных измерениях диалога; отрицание Я-неизвестного в рефлексивном диалоге.

Регрессирующее самотождество: низкий уровень смыслового освоения и реализации ОО; неосознанные противоречия актов отождествления и разотождествления Я с собой в аспекте ОО; «выпадение» большинства измерений рефлексивного диалога.

Невыраженное самотождество: отсутствие смыслового освоения и реализации ОО; невключенность Я в рефлексивный диалог.

Участница исследования, интервью которой мы привели выше, обладает «развивающимся самотождеством», отличающимся готовностью личности к расширению и обновлению своего «бытия самим собой». Респонденты, обладающие данной формой, а также становящимся и противоречивым самотождеством, составили $62 \%$ выборки и продемонстрировали позитивный опыт Я в разрешении парадокса отождествления-разотождествления Я с собой на пути достижения самотождественности посредством Другого.

\section{Литература}

Андреева, Г. М. (2009). Личность в поисках идентичности в глобальном мире. В кн. Социальная психология сегодня: поиски и размыєиления (с. 123-125). М.: Изд-во МПСИ. 
Белинская, Е. П. (2018). Современные исследования идентичности: от структурной определенности к процессуальности и незавершенности. Вестник Санкт-Петербургского университета. Психология и педагогика, 8(1), 6-15. https://doi.org/10.21638/11701/spbu16.2018.101

Бунин, И. А. (2004). Жизнь Арсеньева. СПб.: Азбука-классика.

Леонтьев, Д. А. (2009). Лабиринт идентичностей: не человек для идентичности, а идентичность для человека. Философские науки, 10, 5-10.

Петровский, В. А., Старовойтенко, Е. Б. (2012). Наука личности: четыре проекта общей персонологии. Психология. Журнал Высшей школь экономики, 9(1), 21-39.

Рубинштейн, С. Л. (1973). Проблемь общей психологии. М.: Просвещение.

Сартр, Ж.-П. (2002). Бытие и ничто. Опыт феноменологиеской онтологии. М.: Республика.

Старовойтенко, Е. Б. (2015). Персонология: жизнь личности в культуре. М.: Академический проект.

Старовойтенко, Е. Б. (2019). Самотождество Я во внутреннем диалоге. Психология. Журнал Высшей школь экономики, 16(3), 434-456. https://doi.org/10.17323/1813-8918-2019-3-434-456

Старовойтенко, Е. Б. (2020). Парадоксы достижения самотождества Я: герменевтическая модель. Мир психологии. Научно-методический журнал, 102(2), 118-134.

Старовойтенко, Е. Б., Щебетенко, С. А. (2020). Я-Неизвестное в достижении самотождества и самопреобразовании личности. Психология. Журнал Высшей школь экономики, 17(4), 757-778. https://doi.org/10.17323/1813-8918-2020-4-757-778

Ссылки на зарубежные источники см. в разделе References.

\section{References}

Andreeva, G. M. (2009). Lichnost' v poiskakh identichnosti v global'nom mire [Personality in the search of identity in the global world]. In Sotsial'naya psikhologiya segodnya: poiski i razmyshleniya [Social psychology today: search and thoughts] (pp. 123-125). Moscow: MPSI.

Anthony, A. K., \& McCabe, J. (2015). Friendship talk as identity work defining the self through friend relationships. Symbolic Interaction, 38(1), 64-82. https://doi.org/10.1007/s10804-013-9156-8

Aron, A., \& Aron, E. N. (1995). Falling in love: Prospective studies of self-concept change. Journal of Personality and Social Psychology, 69(6), 1102-1112. https://doi.org/10.1037/0022-3514.69.6.1102

Aron, A., Aron, E. N., Tudor, M., \& Nelson, G. (1991). Close relationships as including other in the self.Journal of Personality and Social Psychology, 60(2), 241-253. https://doi.org/10.1037/0022-3514.60.2.241

Belinskaya, E. P. (2018). Modern identity studies: from structural certainty to procedural incompleteness. Vestnik Sankt-Peterburgskogo Universiteta. Psikhologiya i Pedagogika, 8(1), 6-15. https://doi.org/10.21638/11701/spbu16.2018.101 (in Russian)

Bem, D. J. (1972). Self-perception theory. Experimental social psychology. New York, NY; London, England: Academic Press.

Breen, A. V., Lewis, S. P., \& Sutherland, O. (2013). Brief report: Non-suicidal self-injury in the context of self and identity development. Journal of Adult Development, 20(1), 57-62. https://doi.org/10.1007/s10804-013-9156-8

Brinkmann, S. (2008). Identity as self-interpretation. Theory $\mathcal{F}$ Psychology, 18(3), 404-422.

Bunin, I. A. (2004). Zhizn' Arsen'eva [The life of Arseniev]. Saint Petersburg: Azbuka-klassika.

Costas, J., \& Kärreman, D. (2016). The bored self in knowledge work. Human Relations, 69(1), 61-83. https//doi.org/10.1177/0018726715579736 
Emery, L. F., Walsh, C., \& Slotter, E. B. (2015). Knowing who you are and adding to it: Reduced selfconcept clarity predicts reduced self-expansion. Social Psychological and Personality Science, 6(3), 259-266. https//doi.org/10.1177/1948550614555029

Ginev, D. (2009). From existential conception of science to hermeneutic phenomenology of scientific research.Journal of Philosophical Research, 34, 365-389. https://doi.org/10.5840/jpr_2009_21

Ginev, D. (2012). Two accounts of the hermeneutic fore-structure of scientific research. International Studies in the Philosophy of Science, 26(4), 423-445. https://doi.org/10.1080/02698595.2012.748498

Ginev, D. (2013). Ethnomethodological and hermeneutic-phenomenological perspectives on scientific practices. Human Studies, 36(2), 277-305. https://doi.org/10.1007/s10746-013-9264-2

Ginev, D. (2014). Radical reflexivity and hermeneutic pre-normativity. Philosophy and Social Criticism, 40(7), 683-703. https://doi.org/10.1177/0191453714536432

Ginev, D. (2019). The dialogical self from the viewpoint of hermeneutic phenomenology. Culture and Psychology, 25(3), 275-301. https://doi.org/10.1177/1354067X17738982

Grimell, J. (2018). Advancing an understanding of selves in transition: I-positions as an analytical tool. Culture and Psychology, 24(2), 190-211. https://doi.org/10.1177/1354067X17707451

Gurung, R. A. Sarason, B. R., \& Sarason, I. G. (2001). Predicting relationship quality and emotional reactions to stress from significant-other-concept clarity. Personality and Social Psychology Bulletin, 27 (10), 1267-1276. https://doi.org/10.1177/01461672012710003

Hermans, H. J. M. (2001). The dialogical Self: Toward a theory of personal and cultural positioning. Culture and Psychology, 7(3), 243-281.

Iversen, A. (2019). Reflexive positioning in identity work: When the shoe does not fit... Scandinavian Psychologist, 6. https://doi.org/10.15714/scandpsychol.6.e8

Johnson, J. T., Robinson, M. D., \& Mitchell, E. B. (2004). Inferences about the authentic self: When do actions say more than mental states? Journal of Personality and Social Psychology, 87(5), 615-630. https://doi.org/10.1037/0022-3514.87.5.615

Konopka, A., Neimeyer, R. A., \& Jacobs-Lentz, J. (2018). Composing the self: Toward the dialogical reconstruction of self-identity. Journal of Constructivist Psychology, 31(3), 308-320. https://doi.org/10.1080/10720537.2017.1350609

Leontiev, D. A. (2009). Labirint identichnostei: ne chelovek dlya identichnosti, a identichnost' dlya cheloveka [Identities' labyrinth: not a man for identity, but identity for a man]. Filosofskie Nauki, 10, 5-10.

Lichtenberg, J. D. (2017). Narrative contributions to the core sense of self, identity, and individuality. In J. D. Lichtenberg et al. (Eds.), Narrative and meaning: The foundation of mind, creativity, and the psychoanalytic dialogue (pp. 229-240). Routledge. https://doi.org/10.4324/9781315205212

Mallett, O., \& Wapshott, R. (2012). Mediating ambiguity: Narrative identity and knowledge workers. Scandinavian Journal of Management, 28(1), 16-26. https://doi.org/10.1016/j.scaman.2011.12.001

Marková, I., \& Novaes, A. (2020). Chronotopes. Culture \& Psychology, 26(1), 117-138. https://doi.org/10.1177/1354067X19888189

Mashek, D., Aron, A., \& Boncimino, M. (2003). Confusions of self with close others. Personality and Social Psychology Bulletin, 29(3), 382-392.

Petrovsky, V. A., Starovoitenko, E. B. (2012). The science of personality: Four projects of general personology. Psychology. Journal of Higher School of Economics, 9(1), 21-39. (in Russian)

Raggatt, P. T. F. (2014). The dialogical self as a time-space matrix: Personal chronotopes and ambiguous signifiers. New Ideas in Psychology, 32, 107-114.

Rubinstein, S. L. (1973). Problemy obshchei psikhologii [Issues of general psychology]. Moscow: Prosveshchenie. 
Sartre, J.-P. (2002). Bytie i nichto. Opyt fenomenologicheskoi ontologii [Being and nothingness. An essay on phenomenological ontology]. Moscow: Respublika. (Original work published 1943 in French)

Schlegel, R. J., Hicks, J. A., Arndt, J., \& King, L. A. (2009). Thine own self: True selfconcept accessibility and meaning in life. Journal of Personality and Social Psychology, 96(2), 473-490. https://doi.org/10.1037/a0014060

Starovoitenko, E. B. (2015). Personologiya: zhizn' lichnosti v kul'ture [Personology: the life of personality in culture]. M.: Akademicheskii proekt.

Starovoitenko, E. B. (2019). Self-identity of the I in internal dialog. Psychology. Journal of Higher School of Economics, 16(3), 434-456. https://doi.org/10.17323/1813-8918-2019-3-434-456 (in Russian)

Starovoitenko, E. B. (2020). Paradoxes of achieving self-identity: hermeneutical model. Mir Psikhologii, 102(2), 118-134. (in Russian)

Starovoitenko, E. B., Shchebetenko, S. A. (2020). Unknown self in reaching self-identity and selftransformation. Psychology. Journal of Higher School of Economics, 17(4), 757-778. https://doi.org/10.17323/1813-8918-2020-4-757-778 (in Russian)

Starovoytenko, E. B. (2020). Models of the dialogical achievement of the I's self-identity. Psychology. PSY. Higher School of Economics. No. WP BRP 117/PSY. https://publications.hse.ru/preprints/374625477 Strohminger, N., Knobe, J., \& Newman, G. (2017). The true self: A psychological concept distinct from the self. Perspectives on Psychological Science, 12(4), 551-560. https://doi.org/10.1177/1745691616689495

Tomassini, M. (2015). Reflexivity, self-identity and resilience in career development: Hints from a qualitative research study in Italy. British Journal of Guidance and Counselling, 43(3), 263-277. https//doi.org/10.1080/03069885.2015.1028890 